\title{
Recommendations for core critical care ultrasound competencies as a part of specialist training in multidisciplinary intensive care: a framework proposed by the European Society of Intensive Care Medicine (ESICM)
}

Adrian Wong ${ }^{1,2^{*}}$ D, Laura Galarza ${ }^{1,3}$, Lui Forni ${ }^{1,4}$, Daniel De Backer ${ }^{5}$, Michael Slama ${ }^{6}$, Bernard Cholley ${ }^{7}$, Paul Mayo ${ }^{8}$, Anthony McLean ${ }^{9}$, Antoine Vieillard-Baron ${ }^{10}$, Daniel Lichtenstein ${ }^{11}$, Giovanni Volpicelli ${ }^{12}$, Robert Arntfield ${ }^{13}$, Ignacio Martin-Loeches ${ }^{1,14}$, Gizella Melania Istrate ${ }^{1}$, František Duška ${ }^{1,15}$ on behalf of ESICM Critical Care Ultrasound Group

Abstract: Critical care ultrasound (CCUS) is an essential component of intensive care practice. Although existing international guidelines have focused on training principles and determining competency in CCUS, few countries have managed to operationalize this guidance into an accessible, well-structured programme for clinicians training in multidisciplinary intensive care. We seek to update and reaffirm appropriate CCUS scope so that it may be integrated into the international Competency-based Training in Intensive Care Medicine. The resulting recommendations offer the most contemporary and evolved set of core CCUS competencies for an intensive care clinician yet described. Importantly, we discuss the rationale for inclusion but also exclusion of competencies listed.

Background/aim: Critical care ultrasound (CCUS) is an essential component of intensive care practice. The purpose of this consensus document is to determine those CCUS competencies that should be a mandatory part of training in multidisciplinary intensive care.

Methods: A three-round Delphi method followed by face-to-face meeting among 32 CCUS experts nominated by the European Society of Intensive Care Medicine. Agreement of at least $90 \%$ of experts was needed in order to enlist a competency as mandatory.

Results: The final list of competencies includes 15 echocardiographic, 5 thoracic, 4 abdominal, deep vein thrombosis diagnosis and central venous access aid.

Conclusion: The resulting recommendations offer the most contemporary and evolved set of core CCUS competencies for an intensive care clinician yet described.

Keywords: Core critical care ultrasound, Specialist training, Competencies, Education in intensive care

\footnotetext{
* Correspondence: avkwong@mac.com

${ }^{1}$ European Society of Intensive Care Medicine, Brussels, Belgium

${ }^{2}$ Department of Critical Care, King's College Hospital, London, UK

Full list of author information is available at the end of the article
}

(c) The Author(s). 2020 Open Access This article is licensed under a Creative Commons Attribution 4.0 International License, which permits use, sharing, adaptation, distribution and reproduction in any medium or format, as long as you give appropriate credit to the original author(s) and the source, provide a link to the Creative Commons licence, and indicate if changes were made. The images or other third party material in this article are included in the article's Creative Commons licence, unless indicated otherwise in a credit line to the material. If material is not included in the article's Creative Commons licence and your intended use is not permitted by statutory regulation or exceeds the permitted use, you will need to obtain permission directly from the copyright holder. To view a copy of this licence, visit http://creativecommons.org/licenses/by/4.0/. The Creative Commons Public Domain Dedication waiver (http://creativecommons.org/publicdomain/zero/1.0/) applies to the data made available in this article, unless otherwise stated in a credit line to the data. 


\section{Introduction}

In 2009, the CHEST journal published the ACCP/SRLF Statement on Competency in Critical Care Ultrasonography [1]. This was a cooperative project between French and North American colleagues that led to an additional document that was published in 2011 titled Training Standards for Critical Care Ultrasonography. The training statement was prepared and approved by a working group of 22 professional societies from around the world including major societies from North America [2]. The competency statement was adopted as the foundation document for the training statement. A similar working group was brought together in 2014 and formulated the training statement on Competency in Advanced Critical Care Echocardiography (ACCE). This statement used the principles established in the ACCP/ SRLF statement and forms the basis for the certification in ACCE that is now available in North America and Europe [3].

Critical care ultrasound (CCUS) is an essential component of intensive care practice. Although existing international guidelines have focused on training principles and determining competency in CCUS [1-3], few countries have managed to operationalize this guidance into an accessible, well-structured programme for clinicians training in multidisciplinary intensive care $[4,5]$. It is thus incumbent upon CCUS leaders to review existing competencies specifically with the purpose of informing robust national training programmes within the framework defined by the European Union of Medical Specialists [5] and clarify any confusion that may have arisen since the initial guidelines were launched almost a decade ago.

We aimed to address this need by clearly defining the required competencies, so that they may be integrated into critical care function. The goal of this document is to provide specific guidance to the international critical care community by establishing unambiguous standards for training and competency in CCUS. The primary criterion is that all core competencies need to be of clinical value in the general intensive care setting. A further consideration is that these competencies need to be deliverable by trainers across a wide range of critical care settings.

\section{Methods}

Following a systematic review of international CCUS training schemes [3], ESICM representatives (AW, LG, FD) approached the corresponding authors of the existing guidelines $[1,3]$ to form a core group of 15 experts, including 2 educators, a trainee and a consultant educationalist. Subsequently, members of relevant ESICM subcommittees and CCUS experts nominated by ESICM Council national representatives were invited to form an extended group of 17 additional experts. The combined (core and extended) CCUS group of experts and action plan were endorsed by both the ESICM Executive Committee and CoBaTrICe Committee (Competency-Based Training programme in Intensive Care Medicine for Europe).

A modified Delphi exercise was performed using webbased questionnaires and a final face-to-face round between June and September 2019 [6]. The Delphi technique was chosen as it allowed the exploration of a field beyond existing knowledge, discussion among experts and formation of consensus; the modified version was chosen because it allowed for expert interaction in the final round. The questionnaire was designed with questions based on a 5-point Likert scale [7], ranging from 'strongly disagree' to 'strongly agree', without a default answer setting to avoid influencing the experts' responses. Questions were organized by domains per page and with nearly any matrix to minimize straightlining phenomenon. Throughout the whole process, the answers were evaluated by AW, LG and FD to identify inconsistencies in response patterns of individual members or heterogeneous answers. In these cases, members were contacted to ascertain their understanding of the question and confirm that it had not been an error during questionnaire completion.

The first exploratory survey was conducted within the core group to evaluate the intelligibility of the questions and completeness of the questionnaire. The first round with the combined group included closed questions and a free-text response within each domain, providing the opportunity to elaborate their responses. The second round included the original statements plus those derived from the free-text answers in the first round. This was supplemented by a face-to-face meeting of the core group.

After each round, we calculated basic descriptive statistics (median and IQR) for each statement; a summary of the survey results was sent to the combined group. In order to provide a recommendation, the combined group a priori agreed that the degree of required consensus be $>80 \%$ of agreement threshold. All competencies were further reviewed during the face-to-face meeting with the goal of reaching an agreement level of $>90 \%$.

The steps of the process are summarized in Fig. 1.

\section{Results}

Thirty-two selected experts were invited and agreed to participate in this Delphi exercise, all of whom completed the exercise. We had a response rate of $100 \%$ for all questions in all rounds. Thirteen experts attended the face-to-face meeting, with the remaining two unable to attend due to conflicting obligations. A full list of experts is provided in Supplementary material 1.

In the exploratory round, six domains and fifty-eight statements were proposed. Minor changes regarding completeness were made. In the first round, we were able to obtain consensus in 27 statements. All free-text comments were 
Exploratory round (Core group): To define the list of items to submit for panel evaluation.

Suggestions for content modification and rewording of questions

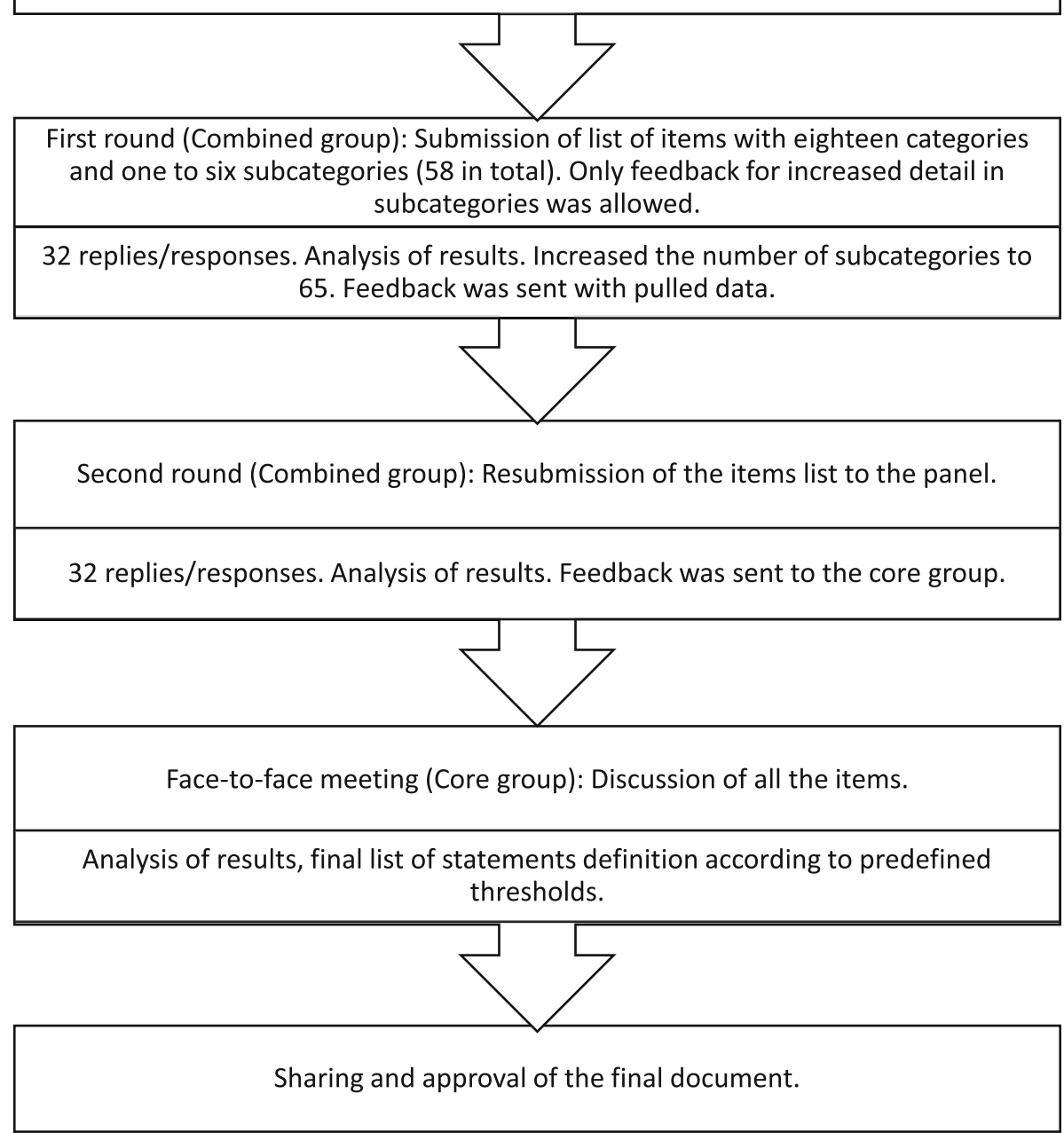

Fig. 1 Flowchart summarizing the steps of the process

Table 1 Summary of Delphi exercise

\begin{tabular}{|c|c|c|c|c|c|c|}
\hline \multirow[t]{2}{*}{ Domains } & \multicolumn{3}{|c|}{ Number of statements in each domain } & \multicolumn{3}{|c|}{ Proportion of statements where consensus was achieved } \\
\hline & Round 1 & Round 2 & Face-to-face & Round $1(\%)$ & Round 2 (\%) & Face-to-face (\%) \\
\hline Echocardiography & 31 & 36 & 36 & 51.6 & 55.6 & 83.3 \\
\hline Thoracic & 6 & 6 & 6 & 83.3 & 83.3 & 83.3 \\
\hline Diaphragm & 3 & 4 & 4 & 0 & 0 & 50 \\
\hline Abdominal & 6 & 7 & 7 & 33.3 & 33.3 & 85.7 \\
\hline Vascular & 6 & 6 & 6 & 66.6 & 83.3 & 83.3 \\
\hline Other modalities & 6 & 6 & 6 & 0 & 0 & 83.3 \\
\hline Totals & 58 & 65 & 65 & 46.6 & 49.2 & 81.5 \\
\hline
\end{tabular}

Consensus was achieved when $80 \%$ of the participants strongly agreed/agreed or strongly disagreed/disagreed with a statement in round 1 and 2 . In face-to-face meeting, consensus was achieved when $90 \%$ of participants agreed or disagreed 
Table 2 Results of the Delphi process with the full competencies explored

\begin{tabular}{|c|c|c|c|}
\hline & \multicolumn{2}{|l|}{ Agreement } & \multirow[t]{2}{*}{ No agreement } \\
\hline & Include & Not to include & \\
\hline \multicolumn{4}{|c|}{ Echocardiography } \\
\hline Syndromes & $\begin{array}{l}\text { Severe hypovolemia } \\
\text { LV failure } \\
\text { RV failure } \\
\text { Tamponade } \\
\text { Acute cor pulmonale } \\
\text { Severe valvular abnormalities }\end{array}$ & Post-cardiac arrest management* & \\
\hline Left ventricle & $\begin{array}{l}\text { Size (qualitative) } \\
\text { Systolic function (qualitative) } \\
\text { Contraction pattern (qualitative) } \\
\text { Valvular disease (qualitative: colour doppler) }\end{array}$ & $\begin{array}{l}\text { Systolic function (quantitative: } \\
\text { Simpson, Teicholz) } \\
\text { Diastolic function (quantitative) } \\
\text { Contraction pattern (quantitative) } \\
\text { Valvular disease (quantitative) }\end{array}$ & $\begin{array}{l}\text { Size (quantitative: diameter and } \\
\text { wall thickness) } \\
\text { Systolic function (quantitative: } \\
\text { MAPSE, aortic VTI) }\end{array}$ \\
\hline $\begin{array}{l}\text { Right } \\
\text { ventricle }\end{array}$ & $\begin{array}{l}\text { Size (qualitative) } \\
\text { Systolic function (quantitative: TAPSE, RV/LV ratio) } \\
\text { Valvular disease (qualitative: colour doppler) }\end{array}$ & $\begin{array}{l}\text { Size (quantitative) } \\
\text { Valvular disease (quantitative) }\end{array}$ & \\
\hline $\begin{array}{l}\text { Inferior vena } \\
\text { cava }\end{array}$ & $\begin{array}{l}\text { Size (quantitative) } \\
\text { Respiratory variation (quantitative) }\end{array}$ & & \\
\hline Procedures & & & Pericardiocentesis \\
\hline \multicolumn{4}{|c|}{ Thoracic ultrasound } \\
\hline Syndromes & $\begin{array}{l}\text { Consolidation }{ }^{* *} \\
\text { Pleural effusion } \\
\text { Interstitial syndrome*** } \\
\text { Pneumothorax }\end{array}$ & & \\
\hline Procedures & $\begin{array}{l}\text { Pleural effusion drainage (thoracentesis and/or } \\
\text { intercostal drain insertion) }\end{array}$ & & Tracheostomy \\
\hline \multicolumn{4}{|c|}{ Diaphragm ultrasound } \\
\hline & & $\begin{array}{l}\text { Thickness } \\
\text { Thickening fraction }\end{array}$ & Excursion \\
\hline \multicolumn{4}{|c|}{ Abdominal ultrasound } \\
\hline & $\begin{array}{l}\text { Free fluid } \\
\text { Bladder volume (qualitative) } \\
\text { Hydronephrosis (qualitative) }\end{array}$ & $\begin{array}{l}\text { Liver and biliary tree (cholecystitis) } \\
\text { Renal resistive index } \\
\text { Hydronephrosis (quantitative) }\end{array}$ & Aorta \\
\hline Procedures & Ascites drainage & & \\
\hline \multicolumn{4}{|c|}{ Vascular ultrasound } \\
\hline Syndromes & DVT (proximal 3-point compression)***** & DVT (Doppler) & \\
\hline $\begin{array}{l}\text { Vascular } \\
\text { access }\end{array}$ & $\begin{array}{l}\text { Femoral vein } \\
\text { Jugular vein } \\
\text { Radial artery } \\
\text { Femoral artery }\end{array}$ & & Subclavian vein \\
\hline \multicolumn{4}{|c|}{ Other modalities } \\
\hline & & $\begin{array}{l}\text { Nerve block } \\
\text { Muscle } \\
\text { Skin and soft tissue } \\
\text { Optic nerve sheath diameter } \\
\text { Airway management }\end{array}$ & Transcranial Doppler \\
\hline
\end{tabular}

LV left ventricle, $R V$ right ventricle, MAPSE mitral annulus plane systolic excursion, $V T I$ velocity time integral, TAPSE tricuspid annulus plane systolic excursion, DVT deep vein thrombosis

*Post-cardiac arrest care was perceived to have no specificities; most of the features are covered by assessment of hypovolemia/right ventricle/left ventricle/ tamponade/severe valvular dysfunction as reported in the left column

${ }^{*}$ Consolidation refers to different pulmonary conditions characterized by different degrees of loss of aeration and increase in density, such as infection, contusion, infarction or atelectasis [8]

***Interstitial syndrome refers to a collection of conditions affecting the lung interstitium characterized by increased B-lines generated by juxtaposition of alveolar air and septal thickening (from fluid or fibrosis) [8]

${ }^{* * * *}$ Qualitative measurement refers to yes/no answer

*****Three-point compression method involves compression at (1) common femoral vein and saphenofemoral junction, (2) popliteal vein and (3) mid-thigh level 
- Hynek Riha, Department of Anaesthesia and Intensive Care, Institute for Clinical and Experimental Medicine, Prague, Czech Republic

- Christoph Ganter, Institute of Intensive Care Medicine, University Hospital Zürich, Zurich, Switzerland

- João Santos Silva, Department of Intensive Care, Hospital Santa MariaCentro Hospitalar Universitario Lisboa NorteLisbonPortugal

- Lucia Lopez-Rodriguez, Department of Intensive Care, Hospital Universitario de Getafe, Getafe, Spain

- Miguel Tavares, Department of Intensive Care, Santo António General

Hospital, Porto, Portugal

- Jan Benes, Department of Anesthesiology and Intensive Care Medicine,

Faculty of Medicine in Plzeň, Charles University, Plzeň, Czech Republic

- Gernot Gorsewski, Department of Anaesthesia and Intensive Care, State Hospital Feldkirch, Feldkirch, Austria

- Jesús-Andrés Álvarez-Fernández, Department of Intensive Care, Hospital Universitario de Getafe, Getafe, Spain

- Sara Sher, Department of Intensive Care, Ospedale Niguarda Ca'Granda, Milan, Italy

- Reto Etter, Department of Intensive Care, Spitalzentrum Biel, Biel, Switzerland

- Peter Faybik, Department of Anesthesia, Intensive Care, and Pain Therapy, Medical University of Vienna, Austria

- Michelle Chew, Department of Anesthesiology and Intensive Care, Medica and Health Sciences, Linköping University, Linköping, Sweden

- Thomas Hamp, Department of Anesthesia, Intensive Care, and Pain Therapy, Medical University of Vienna, Austria

\section{Authors' contributions}

AW and LG developed the idea for the project. AW, LG, FD and MI developed the Delphi methodology. AW was responsible for the first draft of the manuscript. LG performed the analysis of the results. The other authors formed part of the core group, contributing to the questionnaire development, took part in the discussion and contributed to the refinement of the various drafts of the manuscript. The authors read and approved the final manuscript.

\section{Funding}

The open-access fees for publication will be funded by Frantisek Duska and his department at the Charles University Prague

\section{Availability of data and materials}

Not applicable

\section{Ethics approval and consent to participate}

Not applicable

\section{Consent for publication}

Not applicable

\section{Competing interests}

The authors declare that they have no competing interests.

\section{Author details}

${ }^{1}$ European Society of Intensive Care Medicine, Brussels, Belgium. ${ }^{2}$ Department of Critical Care, King's College Hospital, London, UK. ${ }^{3}$ Department of Intensive Care, Hospital General Universitario de Castellon, Castellon de la Plana, Spain. ${ }^{4}$ Department of Intensive Care, Royal Surrey County Hospital, Guildford, UK. ${ }^{5}$ Department of Intensive Care, CHIREC Hospitals, Université Libre de Bruxelles, Brussels, Belgium. ${ }^{6}$ Medical Intensive Care, DRIME department in University Hospital of Amiens, Amiens, France. ${ }^{7}$ Service d'Anesthésie-Réanimation, Hôspital Européen Georges Pompidou, AP-HP, Paris, France. ${ }^{8}$ Division of Pulmonary, Critical Care, and Sleep Medicine, Northshore/Long Island Jewish Medical Centers, Northwell Health, New Hyde Park, NY, USA. ${ }^{9}$ Department of Intensive Care Medicine, Nepean Hospital, University of Sydney, Sydney, Australia. ${ }^{10}$ Unit of Medical-Surgical Intensive Care, Ambroise Paré University Hospital, Assistance

Publique-Hôpitaux de Paris, Boulogne-Billancourt, France. ${ }^{11}$ Medical Intensive Care Unit, Hospital Ambroise-Paré (AP-HP), Boulogne (Paris-Ouest university), Boulogne-Billancourt, France. ${ }^{12}$ Department of Emergency Medicine, San Luigi Gonzaga University Hospital, Orbassano, Torino, Italy. ${ }^{13}$ Division of Critical Care, Department of Medicine, Western University London, Ontario,
Canada. ${ }^{14}$ St James's Hospital, Multidisciplinary Intensive Care Research Organization (MICRO), Dublin, Ireland. ${ }^{15}$ Department of Anaesthesia and Intensive Care, Charles University, Third Faculty of Medicine and FNKV University Hospital in Prague, Prague, Czech Republic.

Received: 4 May 2020 Accepted: 17 June 2020

Published online: 03 July 2020

\section{References}

1. Expert Round Table on Ultrasound in ICU. International expert statement on training standards for critical care ultrasonography. Intensive Care Med. 2011;37:1077-83.

2. Expert Round Table on Echocardiography in ICU. International consensus statement on training standards for advanced critical care echocardiography. Intensive Care Med 2014; 40:654-666.

3. Mayo PH, Beaulieu Y, Doelken P, Feller-Kopman D, Harrod C, Kaplan A, Oropello J, Vieillard-Baron A, Axler O, Lichtenstein D, Maury E. American College of Chest Physicians/La Societe de Reanimation de Langue Francaise statement on competence in critical care ultrasonography. Chest. 2009; 135(4):1050-60.

4. Wong A, Galarza L, Duska F. Critical care ultrasound: a systematic review of international training competencies and program. Crit Care Med. 2019;47(3): e256-62. https://doi.org/10.1097/CCM.0000000000003626.

5. UEMS European Standards for Postgraduate Medical Specialist Training: Multidisciplinary Intensive Care, available at: https://www.uems.eu/_data/ assets/pdf_file/0004/44437/UEMS-2014.40-European-Training-RequirementsIntensive-Care-Medicine.pdf [last Accessed 03 Nov 2019].

6. Murphy MK, Black NA, Lamping DL, et al. Consensus development methods, and their use in clinical guideline development. Health Technol Assess. 1998:2(3):1-88.

7. Likert R. A technique for the measurement of attitudes. Arch Psychol. 1932; 140:1-55.

8. Volpicelli G, Elbarbary M, Lichtenstein DA, et al. International evidencebased recommendations for point-of-care lung ultrasound. Intensive Care Med. 2012;38:577-91.

9. Avella JR. Delphi panels: research design, procedures, advantages, and challenges. Int J Dr Stud. 2016;11:305-21.

\section{Publisher's Note}

Springer Nature remains neutral with regard to jurisdictional claims in published maps and institutional affiliations. 